\section{Oral surgery: part 3. Temporomandibular disorders}

\author{
J. Durham ${ }^{1}$
}

IN BRIEF
- Suggests that the diagnosis of
temporomandibular disorders (TMDs)
can be simplified by following published
clinical diagnostic criteria.
Outlines the principles of management
of TMDs and provides references to more
detailed explanations.
Highlights that there are three areas of
equal consideration in the management
of TMDs - biomedical, psychological,
and social.

Temporomandibular disorders (TMDs) are a collection of conditions affecting the temporomandibular joint (TMJ), the muscles of mastication and/or associated structures. They are probably one of the most commonly presenting chronic orofacial pain complaints to the dental profession. TMDs are recognised as a chronic illness and exert biopsychosocial effects on the patient and should therefore be managed in a biopsychosocial manner. This chapter will firstly cover the basic anatomy of the TMJ and its associated structures and then go on to discuss the signs and symptoms, aetiology, diagnosis, and broad management options for TMDs.

\section{BASIC ANATOMY OF THE TEMPOROMANDIBULAR JOINT AND ASSOCIATED STRUCTURE}

The following section is not intended as an exhaustive anatomical text but as a brief overview of pertinent structures. Its aim is to help the reader unfamiliar with the area to understand the anatomy behind some of the signs, symptoms and descriptors used later in the chapter.

The temporomandibular joint (TMJ) is located just in front of the ear. It is a synovial joint with a joint capsule surrounding it (Fig. 1) and has a ginglymoarthroidal articulation (gingly - hinge, arthroidal - sliding). It is situated in the glenoid (or mandibular) fossa, formed from

\begin{tabular}{|c|c|}
\hline \multicolumn{2}{|c|}{ ORAL SURGERY* } \\
\hline Part 1. & Introduction \\
\hline Part 2. & Endodontic surgery \\
\hline Part 3. & Temporomandibular disorders \\
\hline Part 4. & $\begin{array}{l}\text { Minimising and managing nerve } \\
\text { injuries and other complications }\end{array}$ \\
\hline \multicolumn{2}{|c|}{$\begin{array}{l}\text { *This series represents chapters } 1,5,7 \text { and } 8 \text { from the BDJ book } \\
\text { A clinical guide to oral diagnosis - book 1, edited by Tara Rentor } \\
\text { and C. Michael Hill. All other chapters are published in the } \\
\text { complete clinical guide available from the BDJ Books online } \\
\text { shop. Some illustrations have been cropped due to limitations } \\
\text { on size and their full labelling/detail is available in the book. }\end{array}$} \\
\hline
\end{tabular}

'Senior Lecturer in Oral Surgery and Orofacial pain, Honorary Consultant Oral Surgeon, NIHR Clinician Scientist, School of Dental Sciences, Newcastle University

Correspondence to: Dr Justin Durham

Email:j.a.durham@ncl.ac.uk

Accepted 16 July 2013

DOI: 10.1038/sj.bdj.2013.950

${ }^{\circledR}$ British Dental Journal 2013; 215: 331-337

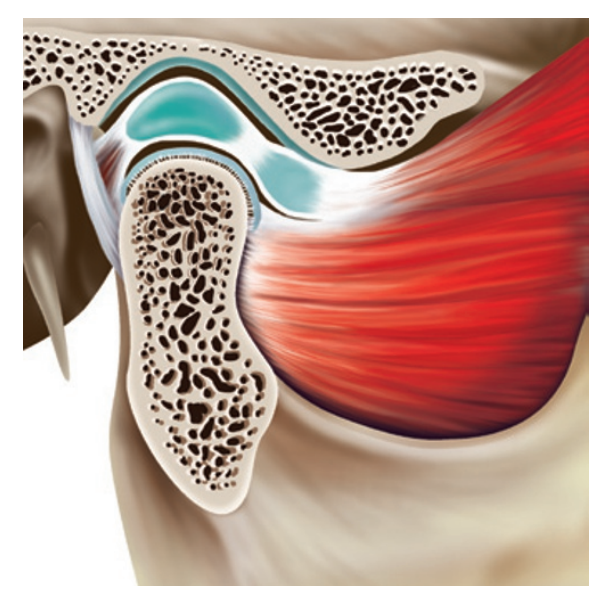

Fig. 1 Articular disc of the

temporomandibular joint

the temporal bone above it. This fossa has an eminence at its anterior margin, the articular eminence. The eminence helps prevent dislocation of the TMJ. In between the condyle (the joint head) and the floor of the glenoid fossa there is a biconcave fibro-cartilaginous connective tissue disc.

The role of the articular disc is controversial; purported functions include creating two joint spaces, upper and lower; adapting to the changing shape of the condyle as it articulates with the bones above; providing decreased friction on the condyle by producing fluid on compression thereby aiding lubrication; and stabilising the condyle's position. ${ }^{1}$ The disc, in 'health', should move relatively synchronously with the condyle as it moves within the fossa.
The disc is specialised for these functions having a number of distinct zones, the description of which is outwith the remit of this book. The most important distinction is that its posterior retrodiscal lamina is heavily innervated with sensory fibres as opposed to the rest of the disc that has minimal innervation. ${ }^{2}$ If, therefore, the disc is displaced out of position and the condyle functions on the posterior retrodiscal lamina it causes a great deal of pain for the patient.

The movement of the TMJ is a complex process but most of the muscles involved are for jaw closing, as the opening of the jaw to a large extent occurs under the influence of gravity, lateral pterygoid and the suprahyoid musculature. The main muscles involved in the movement of the TMJ are a group known collectively as the muscles of mastication. These include the masseter, temporalis, lateral and medial pterygoid.

\section{HISTORICAL PERSPECTIVE, PREVIOUS SYNONYMS AND CURRENT DEFINITION OF TMDS}

Signs and symptoms of TMDs were first recognised by Costen in $1934 .{ }^{3}$ Costen attributed these signs and symptoms to occlusal disharmony and included symptoms such as impaired hearing and oropharyngeal burning sensations alongside the more classical symptoms of pain in the joint and surrounding musculature. 


\section{Table 1 The clinical examination protocol (CEP-TMD) diagnostic criteria for TMDs ${ }^{19}$}

Group

Criteria

Muscle disorders

Myofascial pain

Key: painful muscles

Myofascial pain with limited opening

Key: painful muscles + limited movement

Disc displacements

\section{Disc displacements}

\section{Disc displacement with reduction}

Key: reproducible clicking

Disc displacement without reduction with limited opening

Key: limited opening with no clicking

Disc displacement without reduction without limited opening

Key: history of previously limited opening-imaging needed to confirm disc displacement

\author{
1. Reported pain in masticatory muscles' \\ 2. Pain on palpation in at least three sites, ${ }^{2}$ one of them at least in the same side of the reported pain \\ 1. Myofascial pain \\ 2. Pain-free unassisted ${ }^{3}$ opening $<40 \mathrm{~mm}$ \\ 3. Passive ${ }^{4}$ stretch $\geq 5 \mathrm{~mm}$ (from pain-free unassisted opening to 'painful' assisted opening)
}

1. No pain in the joint neither reported nor on palpation

2. Reproducible ${ }^{5}$ click on any excursion ${ }^{6}$ with either opening or closing click

3. With click on opening and closing (unless excursive click confirmed):

- Click on opening occurs at $\geq 5 \mathrm{~mm}$ interincisal distance than on closing

- Clicks eliminated by protrusive opening

1. History of locking or catching that interfered with eating

2. Absence of TMJ clicking meeting disc displacement reduction (DDR) criteria

3. Unassisted 'painful' opening $\leq 35 \mathrm{~mm}$

4. Passive stretch $<5 \mathrm{~mm}$ (from 'painful' unassisted opening to 'painful' assisted opening)

5. Contralateral excursion $<7 \mathrm{~mm}$ or uncorrected ipsilateral deviation on opening

1. History of locking or catching that interfered with eating

2. The presence of TMJ sounds excluding DDR clicking

3. Unassisted 'painful' opening $>35 \mathrm{~mm}$

4. Passive stretch $\geq 5 \mathrm{~mm}$ (from 'painful' unassisted opening to 'painful' assisted opening)

5. Contralateral excursion $\geq 7 \mathrm{~mm}$

6. Optional imaging (arthrography or MRI) to confirm disc displacement

Other common joint problems

Arthralgia

Key: painful TMJ/no crepitus

1. Pain on TMJ palpation either laterally or intra auricular

2. Self reported joint pain with or without jaw movement

3. Absence of crepitus, and possibility of clicking

1. Pain as for arthralgia (reported and on palpation)

2. Crepitus on any movement or tomographic evidence of joint changes ${ }^{7}$

1. Crepitus on any movement or tomographic evidence of joint changes ${ }^{7}$

2. No reported joint pain, neither on palpation nor on any movement
Costen's syndrome, as TMD was then known, was subject to a number of criticisms and probably represented an amalgam of different orofacial pain conditions.

Shore $^{4}$ in the 1950 s coined the term 'Temporomandibular joint dysfunction syndrome' and, similar to Costen, described the condition in relation to occlusal disturbance. It was not until the 1980s that recognition of the multifaceted biopsychosocial nature of TMDs caused $\mathrm{Bell}^{5}$ to use the phrase by which the condition is now known.

The American Academy of Orofacial Pain defines TMDs as:

'A collective term embracing a number of clinical problems that involve the masticatory musculature, the temporomandibular joint and associated structures, or both. They [TMD] are considered to be a sub classification of musculoskeletal disorders.'

Other previous synonyms for TMDs include: myofascial-pain dysfunction, 


\section{Table 2 Types of temporomandibular disorder}

Temporomandibular disorders (TMDs) refers to three groups of conditions: $:^{18}$

1. Myofascial pain (pain from the masticatory musculature):

- With limited opening

- Without limited opening

2. Disc displacement (abnormal movement of the articular disc):

- With reduction of the disc (clicking)

- Without reduction of the disc displacement:

- With limited opening

- Without limited opening

3. Other joint disorders:

- Arthralgia (pain from the temporomandibular joint)

- Osteoarthritis (painful crepitus)

- Osteoarthrosis (an osteoarthritis that is now quiescent)

Other pathology that can affect the temporomandibular joint complex (joint and associated structures) can include:

Tumours - either primary or secondary

Rheumatoid arthritis

Hyper- or hypomobility

Growth disturbances

temporomandibular-pain dysfunction syndrome, facial arthromylagia. The currently accepted, but still debated, terminology is temporomandibular disorders (plural). ${ }^{6}$

\section{SIGNS AND SYMPTOMS OF TMDS}

Prevalence of the signs and symptoms of TMDs varies widely in the literature. This is probably due to differing methodologies in examining prevalence and the fluctuating nature of TMDs' signs and symptoms.

The prevalence of signs and symptoms is higher (20-75\%) than the number of individuals who present for treatment $(2-4 \%)$. The age of presentation is usually between 20 and 40 years of age and the male to female ratio is $1: 1$ for symptoms, but females outnumber males in presenting for management. ${ }^{7-11}$ Suggestions that the difference in gender presentation for treatment is due to gender-linked behaviour are frequent in the literature but are not scientifically supported. ${ }^{8}$

Signs and symptoms of TMDs are clinically variable and often idiosyncratic but they include six broad groups: ${ }^{9,12-14}$

- Muscular tenderness - in face

(masseter, temporalis, medial or lateral pterygoid), neck and

- Shoulders

- Pain - in head, neck and shoulders

- Joint noises - clicking, crepitus (grinding)

- Locking - open (dislocation), closed (inability to open fully)

- Ear complaints - otalgia

- Psychosocial effects.

\section{AETIOLOGY OF TMDS}

There has been no single aetiological factor identified for TMDs and it is likely that the aetiology is complex and multifactorial. A biopsychosocial model has recently been proposed and offers a potential way forward. ${ }^{13}$ There have also been some recent advances in understanding the possible physiological and genetic basis for TMDs. ${ }^{15-17}$

\section{DIAGNOSIS AND SUBTYPES OF TMDS}

\section{Clinical diagnosis and subtypes}

Until 1992, clinical research found it difficult to investigate homogenous groups of specific TMD subtypes. This was because of the lack of a reliable and valid diagnostic index to diagnose the different subtypes of TMDs. The Research Diagnostic Criteria for TMDs (RDC/TMD) helped solve this problem. ${ }^{18}$ It produced a set of valid and reliable diagnostic algorithms by which researchers could ensure they were examining homogenous groups. The three subtypes of TMDs defined by these criteria are detailed in Tables 1 and 2.

The consortium involved in the construction of the RDC/TMD is preparing a shortened version for every day clinical use: the DC/TMD (diagnostic criteria for TMDs). A recent publication, however, highlighted a clinical examination protocol for TMDs (CEP-TMD) for everyday clinical use that produces a parallel diagnosis to that of the RDC/TMD. ${ }^{19}$ The CEP-TMD is demonstrated and available online (http:// www.ncl.ac.uk/dental/AppliedOcclusion/, see Table 1). This is probably the most applicable diagnostic system currently available for everyday clinical use.

\section{Adjunctive use of radiography in diagnosis}

The consensus on plain radiographs such as the dental panoramic tomograph for any of the subtypes of TMDs (myofascial pain, disc displacements, other joint disorders) is that they are not indicated or justified, as they are unlikely to change the clinician's treatment plan. ${ }^{20,21}$ That said, however, few things are absolute and there are some situations where one might choose to perform a plain radiograph for a patient suspected of suffering from a temporomandibular disorder (for instance, if one suspects there is an element of odontogenic pain contributing to the patient's complaint).

If one suspects a sinister or serious pathology mimicking TMDs, after urgent referral, advanced imaging rather than plain imaging would be indicated. For suspected bony pathology, computed tomography (CT), cone beam computed tomography (CBCT), or positron emission tomography (PET) alongside CT can be considered. For suspected soft tissue pathology MRI remains the gold standard imaging modality. ${ }^{22}$

Advanced imaging for the subtypes of TMDs is not mandatory, as careful clinical examination with a robust diagnostic index has been proved to be reliable. 
Advanced imaging would not be indicated or justifiable for myofascial pain that has been diagnosed clinically. The role and benefit of CT and MRI has also been questioned in treatment planning for nonmyofascial TMDs although the basis for this was largely due to the lack of good quality evidence for their use. ${ }^{23}$ The choice of advanced imaging would be between CT/CBCT for hard tissues and MRI for soft tissues. The clinician would have to have a specific justification in mind for ordering either investigation.

\section{PATHOLOGY OF THE TEMPOROMANDIBULAR COMPLEX}

Serious pathology of the temporomandibular complex (TMJ and associated structures) is rare. Primary tumours in the temporomandibular complex are thought to account for less than $1 \%$ of all head and neck tumours ${ }^{24}$ and incidental findings on MRI for TMDs occur in less than $1 \%$ of TMDs. ${ }^{25}$ Metastases to the temporomandibular joint can occur from multiple sites but the most likely are breast, lung, thyroid, kidney and prostate.

Primary malignant tumours in the head and neck can mimic the signs and symptoms of TMDs, but usually also present with some other signs and symptoms that should alert the attending clinician that there may be another cause for the patient's complaints. These 'red flag' signs and symptoms should mandate an urgent referral and they include:

- New signs and symptoms of TMDs presenting for the first time in the advanced age group ( $>60$ years old)

- Ipsilateral lymphadenopathy

- Previous history of malignancy elsewhere in the body and new onset TMDs

- Cranial nerve dysfunction in relation to the complaint, especially in the fifth and seventh cranial nerves

- Profound and near absolute trismus precluding careful oral examination

- Recurrent ipsilateral epistaxis

- Anosmia

- Persistent nasal obstruction or purulent discharge

- Objective ipsilateral hearing loss.

More common benign pathologies are: hypomobility of the joint, hypermobility of the joint (recurrent dislocations), and degenerative inflammatory states such as osteoarthritis (contained with the TMDs subgroup - other joint disorders) and rheumatoid arthritis.

\section{MANAGEMENT OF TMDS}

There is a vast literature around the management of TMDs stretching back several decades. The current literature suffers from a lack of a standardised, valid and reproducible patient-based outcome measure as well as a lack of consistency in diagnosis (especially pre-1992 and the introduction of RDC/TMD). This has led most attempts at meta-analyses of treatments to call for further research and a standardised outcome measure. ${ }^{26-29}$

Given the paucity of good quality evidence to base practice on, and the fact that the majority of TMDs respond well to simple, reversible, conservative therapy it is suggested as the mainstay of initial management once mimicking pathology has been excluded. ${ }^{12,29-32}$ This suggestion has recently been supported by the release of an updated policy statement from the American Association of Dental Research on TMDs. ${ }^{33}$ This states that unless there are 'specific and justifiable indications to the contrary' conservative reversible therapy should form the initial management of TMDs. Conservative reversible therapy was defined by the National Institutes of Health $^{34}$ as including: appropriate analgesia, intraoral appliances, supportive patient education and counselling, physiotherapy and gross occlusal therapy. Gross occlusal therapy pertains to the removal of newly created large interferences for example: a new fixed or removable prosthesis that has altered the occlusion and signs and symptoms of TMDs have occurred immediately after its insertion. It does not relate to full mouth occlusal equilibration.

\section{Conservative reversible therapy}

Given recent evidence on the importance of diagnosis to sufferers of TMDs, all therapy should be preceded by giving the patient a diagnosis, explaining it to them and reassuring them over TMDs' largely benign course. ${ }^{35}$

Conservative therapy in the literature has shown to have between a 68 to 95\% 'success' rate ${ }^{31,32,36-40}$ and TMDs have been shown to have a large response to placebo. ${ }^{31,41-45}$

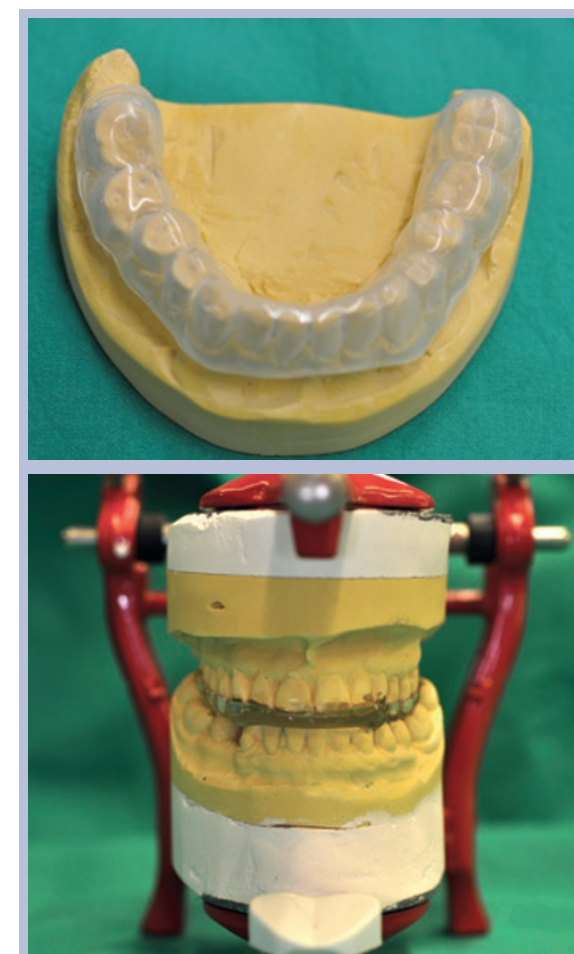

Fig. 2 (a) Lower soft splint; (b) Upper stabilisation splint on average value articulator with incisal guidance pin removed to allow photo. The thickness of beauty hard wax ${ }^{\mathrm{TM}}$ used for the registration determines the thickness of the splint manufactured

Conservative therapies possible for all three subtypes of TMDs (Table 1) are listed below. Citations in the bulleted list generally point the reader towards helpful articles in the literature on these techniques or appliances:

- Physiotherapy and home exercise programmes ${ }^{46,47}$

- Patient physical self-regulatory training, ${ }^{48}$ cognitive behavioural therapy $^{49}$

- Acupuncture ${ }^{50}$ or moist heat applied locally to the masticatory musculature

- Intra-oral appliances, the simplest of these being a lower soft splint (orthotic).

More advanced appliances include the stabilisation splint ${ }^{51,52}$ or an anterior repositioning splint ${ }^{53}$ (Fig. 2). Patients using either stabilisation splints or anterior repositioning splints must be monitored very carefully as there is a potential for occlusal changes to occur with both these splints. Full coverage appliances reduce, but do not eliminate, the possibility of occlusal changes.

Simple pharmacological therapy can help relieve inflammation or pain associated 


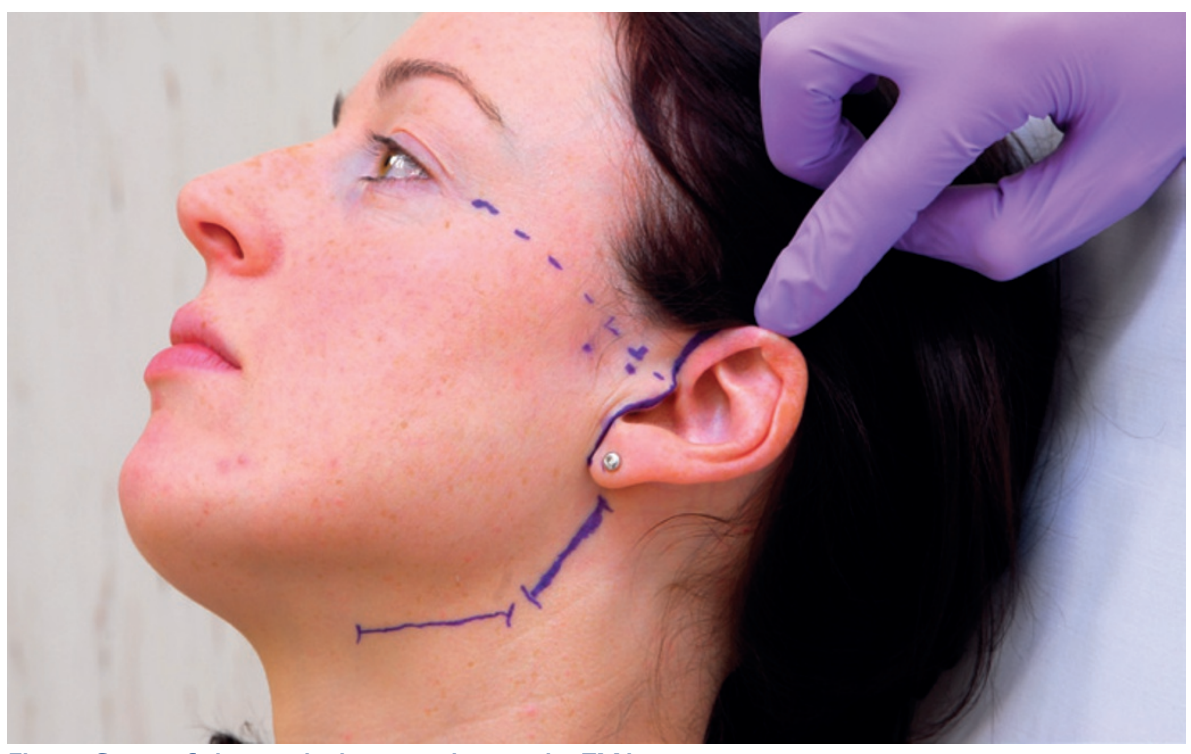

Fig. 3 Some of the surgical approaches to the TMJ

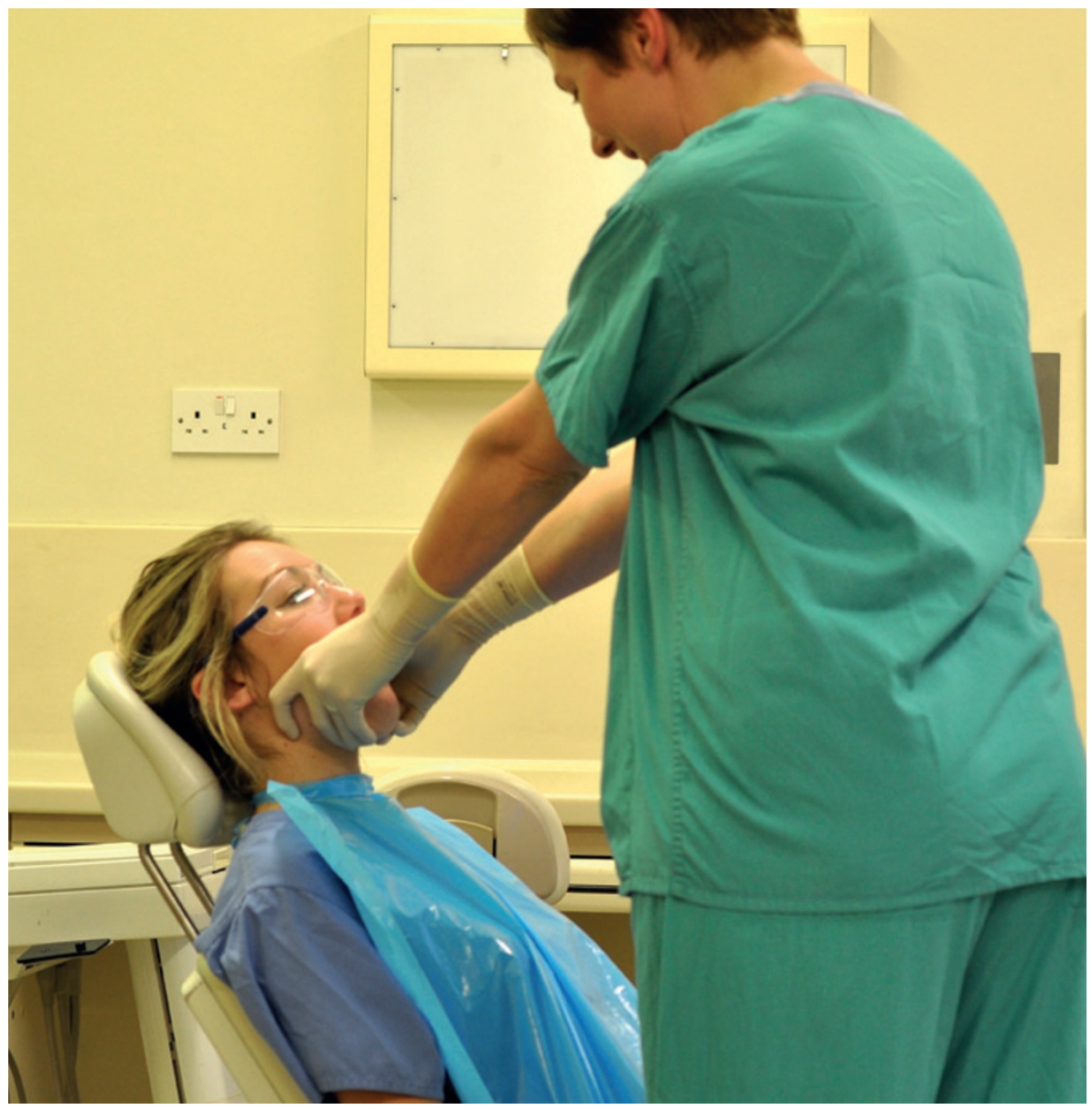

Fig. 4 Stance and positioning for reduction of a dislocated TMJ

with TMDs, for example the judicious use of non-steroidal anti-inflammatory drugs (NSAIDs) when not contraindicated.

These therapies can be used in isolation or, if appropriate, in combination. At present the paucity of evidence does not favour one therapy over another for the particular subtypes of TMDs. It should be noted that in the case of intra-oral appliances a minority of patients' symptoms may worsen when using a lower soft splint, or they may report increased bruxism; in either case the soft splint should be discontinued and consideration should be given to constructing a stabilisation splint.

More advanced conservative therapy initiated by specialists may include the use of centrally acting neuromodulatory pharmacological agents. ${ }^{54-56}$

\section{Irreversible therapy}

It is rare for irreversible therapy to be required due to the high success rate of conservative reversible therapy. Failure of conservative, reversible therapy is not an absolute indication to progress to irreversible therapy.

Two main types of irreversible therapy are reported within the literature. These are occlusal therapy, in the form of occlusal equilibration, and surgery. At present given their irreversible nature and lack of evidence to define the indications for their use these two forms of therapy should not be undertaken without very careful, detailed, consideration of the clinical case and the informed consent of the patient.

The most minimally invasive forms of surgery for TMDs are arthrocentesis and arthroscopy and are probably the more widely used, as opposed to open joint surgery. These two techniques both allow both lysis and lavage of the (upper) joint space(s) and arthroscopy has the additional advantage of allowing some instrumentation and surgery around the joint. Figure 3 shows the position of two of the more commonly used access points for arthroscopy and arthrocentesis along with the retromandibular, submandibular and preauricular approaches to the TMJ. A good description of open approaches to the temporomandibular joint can be found at the AO Foundation (www.aofoundation. org). Sidebottom provides a good review of other less frequently performed open surgical procedures for the temporomandibular complex. ${ }^{57}$

\section{MANAGEMENT OF OTHER PATHOLOGICAL STATES OF THE TEMPOROMANDIBULAR COMPLEX}

It is outwith the remit of this chapter to give extensive details of the management of all pathology affecting the temporomandibular complex. Brief details on the management of the more common benign pathologies will, however, be presented for completeness.

\section{Hypomobility (trismus)}

Hypomobility can be due to a number of causes: mechanical derangement, infective processes, muscular pain, neoplasia, 
inflammatory processes or diseases. Absolute hypomobility can be caused by ankylosis.

Ankylosis is either a fibrous or bony union between the condylar head and the glenoid fossa and can be precipitated by a number of factors including trauma and surgery to the joint. It generally requires surgical management and may necessitate a joint replacement. Suggested guidelines and indications for joint replacement are provided in the UK by the UK TMJ replacement surgeons ${ }^{58}$ and NICE have also recently released guidance on the procedure. ${ }^{59}$

One of the more commonly presenting causes of hypomobility to the general practitioner is that induced by a minor oral surgical procedure or infection near the masseter muscle, for example, pericoronitis of a lower third molar tooth. In the case of the infective origin the source should be removed, drainage instituted and antibiotics prescribed if appropriate. Persisting trismus following resolution of infection or the immediate post-surgical procedure can usually be helped by gentle stretching exercises performed by the patient through the use of increasing numbers of tongue spatulas placed between the incisor teeth. The rare possibility of a pharyngeal or tonsillar tumour should also be considered in cases that fail to resolve rapidly.

\section{Hypermobility}

The most common hypermobile state the general practitioner will encounter is that of a dislocation. This can occur outside of the dental chair (for example, following yawning or trauma), or while in the dental chair (for instance, following excessive unresisted downward force for extraction of lower teeth). The chief signs of a dislocation are a complete inability to occlude the teeth and palpable condylar head(s) outside of the glenoid fossa.

The traditional method for relocation of a dislocated TMJ is for the operator to place their thumbs over the lower molar teeth wrapping their fingers around the inferior body and parasymphysis of the mandible. Slow gentle increasing pressure is then directed down through the lower molars via the operator's thumbs to distract the mandible downwards while their fingers push upward in order to translate the condylar head(s) back over the eminentia (Fig. 4). If there is a bilateral dislocation it is often that one side is easier to reduce than the other and unilateral relocation of the easier side often means the contralateral side then relocates. Once relocated it is possible to use a barrel bandage over the next 24 hours to help prevent a recurrence of the dislocation. A recent wrist-pivot method for relocation of a dislocated mandible has also been described.$^{60}$ This technique and pharmacological interventions (for example, benzodiazepines or general anaesthetic), might be considered should the traditional method of relocation fail.

Patients who have frequent dislocations are not uncommon and there are several surgical and non-surgical methods to attempt to manage this problem. Shorey and Campbell ${ }^{61}$ provide a good review of these treatment options along with their relative 'success' rates.

\section{Rheumatoid arthritis}

This is a chronic, systemic, autoimmune, inflammatory disease causing polyarthritis. It can affect the TMJ and cause problems ranging from pain and crepitus, to resorption of the condylar head and consequential anterior open bite. Most individuals suffering from this disease are under the care of a rheumatologist and management of complaints related to the temporomandibular complex is usually in liaison with a rheumatologist. Open joint surgery, joint replacement and orthognathic surgery can be indicated in more severe cases and therefore it is advisable to have oral and maxillofacial surgery involved at some point in the individual's care. It is important to note that severe resorptive changes as a result of rheumatoid arthritis are not common.

\section{SUMMARY}

Temporomandibular disorders are a collection of three benign conditions that largely respond to conservative reversible therapy. Conservative reversible therapy is the mainstay of initial management and its failure is not an absolute indication for irreversible therapy. Obtaining an accurate diagnosis and excluding other pathology that may mimic TMDs is paramount and once obtained the patient should be informed and reassured over the benign, usually self-limiting nature of TMDs and their excellent response rate to conservative reversible therapy.

1. Standring S. Grey's anatomy. London: Elsevier, 2005

2. Okeson J P. Management of temporomandibular disorders and occlusion. St. Louis: Mosby, 2003.

3. Costen J B. A syndrome of ear and sinus symptoms based on disturbed function of the temporomandibular joint. Ann Otol Rhinol Laryngol 1934; 43: 115.

4. Shore N A. Occlusal equilibration and temporomandibular joint dysfunction. Philadel phia: J B Lipencott, 1959.

5. Bell W E. Clinical management of temporomandibular disorders. Chicago: Year Book Medical Publishers, 1982

6. Laskin D M. Temporomandibular disorders: a term past its time? J Am Dent Assoc 2008; 139: 124-128.

7. Von Korff M, Dworkin S F, Le Resche L, Kruger A. An epidemiologic comparison of pain complaints. Pain 1988; 32: 173-183.

8. de Bont L G, Dijkgraaf L C, Stegenga B. Epidemiology and natural progression of articular temporomandibular disorders. Oral Surg Oral Med Oral Pathol Oral Radiol Endod 1997; 83: 72-76.

9. Grey R J, Davies S J, Quayle A A. A clinical approach to temporomandibular disorders. 1. Classification and functional anatomy. Br Dent J 1994; 176: 429-435

10. De Kanter R J, Käyser A F, Battistuzzi P G, Truin G J, Van't Hof M A. Demand and need for treatment of craniomandibular dysfunction in the Dutch adult population. J Dent Res 1992; 71: 1607-1612.

11. De Kanter R J, Truin G J, Burgersdijk R C et al. Prevalence in the Dutch adult population and a metaanalysis of signs and symptoms of temporomandibular disorder. J Dent Res 1993; 72: 1509-1518.

12. McNeill C. Management of temporomandibular disorders: concepts and controversies. J Prosthet Dent 1997; 77: 510-522.

13. Suvinen $T I$, Reade P C, Kemppainen $P$, Könönen M, Dworkin S F. Review of aetiological concepts of temporomandibular pain disorders: towards a biopsychosocial model for integration of physical disorder factors with psychological and psychosocial illness impact factors. Eur J Pain 2005: 9: 613-633.

14. Turk D C. Psychosocial and behavioural assessment of patients with temporomandibular disorders: diagnostic and treatment implications. Oral Surg Oral Med Oral Pathol Oral Radiol Endod 1997; 83: 65-71.

15. Diatchenko L, Slade G D, Nackley A G et al. Genetic basis for individual variations in pain perception and the development of a chronic pain condition. Hum Mol Genet 2005; 14: 135-143.

16. Light K C, Bragdon E E, Grewen K M, Brownley K A Girdler SS, Maixner W. Adrenergic dysregulation and pain with and without acute beta-blockade in women with fibromyalgia and temporomandibular disorder. J Pain 2009; 10: 542-552.

17. Ribeiro-Dasilva M C, Peres Line S R, Leme Godoy dos Santos M C et al. Oestrogen receptor-alpha polymorphisms and predisposition to TMJ disorder. J Pain 2009; 10: 527-533.

18. Dworkin S F, LeResche L. Research diagnostic criteria for temporomandibular disorders: review, criteria, examinations and specifications, critique. J Craniomandib Disord 1992; 6: 301-355.

19. Hasanain F, Durham J, Moufti A, Steen I N, Wassell $\mathrm{R}$ W. Adapting the diagnostic definitions of the RDC/TMD to routine clinical practice: a feasibility study. J Dent 2009; 37: 955-962.

20. Crow H C, Parks E, Campbell J H, Stucki D S, Daggy J. The utility of panoramic radiography in temporomandibular joint assessment. Dentomaxillofac Radio/ 2005; 34: 91-95.

21. Epstein J B, Caldwell J, Black G. The utility of panoramic imaging of the temporomandibular joint in patients with temporomandibular disorders. Oral Surg Oral Med Oral Pathol Oral Radiol Endod 2001; 92: 236-239.

22. Shintaku W H, Venturin J S, Langlais R P, Clark G T. Imaging modalities to access bony tumours and hyperplasic reactions of the temporomandibular 
joint. J Oral Maxillofac Surg 2010; 68: 1911-1921.

23. Ribeiro-Rotta R F, Marques K D, Pacheco M J, Leles $C R$. Do computed tomography and magnetic resonance imaging add to temporomandibular joint disorder treatment? A systematic review of diagnostic efficacy. J Oral Rehabil 2010; 38: 120-135.

24. Nwoku A L, Koch $\mathrm{H}$. The temporomandibular joint: a rare localisation for bone tumours. J Maxillofac Surg 1974; 2: 113-119.

25. Yanagi Y, Asaumi J, Maki Y et al. Incidentally found and unexpected tumours discovered by MRI examination for temporomandibular joint arthrosis. Eur J Radiol 2003; 47: 6-9.

26. Al-Ani M Z, Davies S J, Grey R J, Sloan P, Glenny A M. Stabilisation splint therapy for temporomandibular pain dysfunction syndrome. Cochrane Database Syst Rev 2004; CD002778.

27. Koh H, Robinson P G. Occlusal adjustment for treating and preventing temporomandibular joint disorders. Cochrane Database Syst Rev 2003; CD003812.

28. Shi Z, Guo C, Awad M. Hyaluronate for temporo mandibular joint disorders. Cochrane Database Syst Rev 2003; CD002970.

29. List T, Axelsson S. Management of TMD: evidence from systematic reviews and meta-analyses. J Oral Rehabil 2010; 37: 430-451.

30. Dimitroulis G. Temporomandibular disorders: a clinical update. BMJ 1998; 317: 190-194.

31. Greene C S, Laskin D M. Long-term evaluation of conservative treatment for myofascial paindysfunction syndrome. J Am Dent Assoc 1974. 89: 1365-1368

32. Greene C S, Laskin D M. Long-term evaluation of treatment for myofascial pain-dysfunction syndrome: a comparative analysis. J Am Dent Assoc 1983; 107: 235-238.

33. Management of patients with TMDs: a new 'Standard of Care'. American Association for Dental Research, 2010

34. Albino J E N. Management of temporomandibular disorders. National Institutes of Health Technology Assessment Conference Statement. J Am Dent Assoc 1996; 127: 1595-1606.

35. Durham J, Steele J G, Wassell R W, Exley C. Living with uncertainty: temporomandibular disorders. J Dent Res 2010; 89: 827-830

36. Sato $S$, Kawamura H, Nagasaka H, Motegi K. The natural course of anterior disc displacement without reduction in the temporomandibular joint: follow-up at 6, 12, and 18 months. J Oral Maxillofac Surg 1997, 55: 234-238; discussion 238-239.

37. Randolph C S, Greene C S, Moretti R, Forbes D, Perry $H \mathrm{~T}$. Conservative management of temporomandibular disorders: a post-treatment comparison between patients from a university clinic and from private practice. Am J Orthod Dentofacial Orthop 1990; 98: 77-82.

38. Magnusson T, Carlsson G E. A two and a half year follow-up of changes in headache and mandibular dysfunction after stomatognathic treatment. J Prosthet Dent 1983; 49: 398-402.

39. Nel H. Myofascial pain-dysfunction syndrome. J Prosthet Dent 1978, 40: 438-441.

40. Carraro J J, Caffesse R G. Effect of occlusal splints on TMJ symptomatology. J Prosthet Dent 1978; 40: 563-536.

41. Greene C S, Laskin D M. Meprobamate therapy for the myofascial pain-dysfunction (MPD) syndrome: a double-blind evaluation. J Am Dent Assoc 1971; 82: 587-590.

42. Greene C S, Laskin D M. Splint therapy for the myofascial pain-dysfunction (MPD) syndrome: a comparative study. J Am Dent Assoc 1972; 84: 624-628.

43. Shipman W G, Greene C S, Laskin D M. Correlation of placebo responses and personality characteristics in myofascial pain-dysfunction (MPD) patients. J Psychosom Res 1974; 18: 475-483.

44. Laskin D M, Greene C S. Influence of the doctorpatient relationship on placebo therapy for patients with myofascial pain-dysfunction (MPD) syndrome. J Am Dent Assoc 1972; 85: 892-894.

45. Goodman P, Greene C S, Laskin D M. Response of patients with myofascial pain-dysfunction syndrome to mock equilibration. J Am Dent Assoc 1976; 92: 755-758.

46. Michelotti A, de Wijer A, Steenks M, Farella M. Home-exercise regimes for the management of nonspecific temporomandibular disorders. J Oral Rehabil 2005; 32: 779-785.

47. Wright E F, Domenech M A Fischer J R J. Usefulness of posture training for patients with temporomandibular disorders. J Am Dent Assoc 2000; 131: 202-210

48. Carlson C R, Bertrand P M, Ehrlich A D, Maxwell A W, Burton R G. Physical self-regulation training for the management of temporomandibular disorders. J Orofac Pain 2001: 15: 47-55.

49. Aggarwal $\vee R$, Tickle $M$, Javidi $H$, Peters S. Reviewing the evidence: can cognitive behavioural therapy improve outcomes for patients with chronic orofacial pain? J Orofac Pain 2010; 24: 163-171.

50. La Touche R, Goddard G, De-la-Hoz J L et al. Acupuncture in the treatment of pain in temporomandibular disorders: a systematic review and meta-analysis of randomized controlled trials. Clin J Pain 2010; 26: 541-550.

51. Moufti M A, Lilico J T, Wassell R W. How to make a well-fitting stabilization splint. Dent Update 2007; 34: 398-400, 402-404, 407-408.

52. Davies S J, Grey R J. The pattern of splint usage in the management of two common temporomandibular disorders. Part II: The stabilisation splint in the treatment of pain dysfunction syndrome. Br Dent J 1997; 183: 247-251.

53. Davies S J, Grey R J. The pattern of splint usage in the management of two common temporomandibular disorders. Part I: The anterior repositioning splint in the treatment of disc displacement with reduction. Br Dent J 1997; 183: 199-203.

54. Hersh E V, Balasubramaniam R, Pinto A. Pharmacologic management of temporomandibula disorders. Oral Maxillofac Surg Clin North Am 2008; 20: 197-210.

55. Kimos P, Biggs C, Mah J et al. Analgesic action of gabapentin on chronic pain in the masticatory muscles: a randomized controlled trial. Pain 2007: 127: 151-60

56. Plesh O, Curtis D, Levine J, McCall W D Jr. Amitriptyline treatment of chronic pain in patients with temporomandibular disorders. J Oral Rehabil 2000; 27: 834-841.

57. Sidebottom A J. Current thinking in temporomandibular joint management. Br J Oral Maxillofac Surg 2009; 47: 91-94.

58. Sidebottom A J. Guidelines for the replacement of temporomandibular joints in the United Kingdom. Br J Oral Maxillofac Surg 2008; 46: 146-147.

59. National Institute for Health and Clinical Excellence. Total prosthetic replacement of the temporomandibular joint. London: NICE, 2009. Online article available at http://www.nice.org.uk/nicemedia/ live/12136/46672/46672.pdf (accessed July 2013).

60. Lowery L E, Beeson M S, Lum K K. The wrist pivot method, a novel technique for temporomandibular joint reduction. J Emerg Med 2004; 27: 167-170.

61. Shorey C W, Campbell J H. Dislocation of the temporomandibular joint. Oral Surg Oral Med Oral Pathol Oral Radiol Endod 2000; 89: 662-668. 